\title{
FEATURE
}

\section{Guidance on handling the touchy subject of \\ sexual harassment}

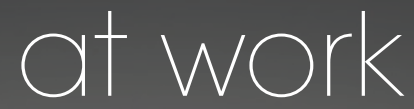

\section{By Fiona McLellan,}

\section{Partner, Hempsons}

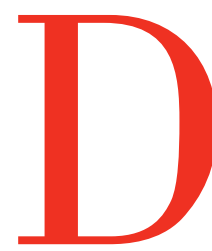

ental practices are often relatively small businesses, which involve close working relationships between staff, as well as close contact with patients and consequently face an increased risk of having to handle difficult allegations of sexual harassment.

This article sets out the statutory framework for sexual harassment in the workplace and provides practical guidance for dealing with these often sensitive, complex and costly cases.

\section{The Equality Act 2010}

The Equality Action 2010 ('EqA') prohibits discrimination in the workplace. Specifically, under the EqA workers are protected against discrimination, including harassment and victimisation related to any of nine prescribed protected characteristics, which include sex and sexual orientation.

The EqA provides protection against discrimination to those in employment which is widely defined and includes individuals working under:

- A contract of employment;

- A contract of apprenticeship; and

- A contract to do work personally.

This means individuals who would ordinarily be classed as self-employed, for example dental associates, are likely to be afforded protection against discrimination if the contract under which they work obliges them to perform the work personally (i.e. they cannot substitute or sub-contract the work to someone else). 


\section{Sex/Sexual Harassment}

The EqA provides protection against three different forms of harassment, specifically:

- Unwanted conduct related to sex that has the purpose or effect of either violating a person's dignity or creating an intimidating, hostile, degrading, humiliating or offensive environment for that person;

- Unwanted conduct of a sexual nature that has the purpose or effect of either violating a person's dignity or creating an intimidating, hostile, degrading, humiliating or offensive environment for that person; and

- Less favourable treatment of a person on account of rejecting or submitting to unwanted conduct of a sexual nature. cases involving junior/younger workers being harassed by senior/older staff; and

- A worker's participation in sexual banter would not preclude conduct being unwanted and harassment. The participation could be a coping mechanism and/or because the worker did not wish to show discontent for fear of reprisals.

\section{What constitutes}

\section{sexual harassment?}

Sexual harassment can take many forms. It can be verbal, non-verbal and/or physical and take the form of: unwelcome advances, touching, sexual jokes, displaying pornographic images or sending material of a sexual nature.

\section{'ISSUES CAN ARISE FOR PRACTICES AND}

\section{INDIVIDUAL EMPLOYEES WHETHER}

\section{INTENTIONAL OR NOT FROM CONDUCT THAT}

\section{CAN CAUSE OFFENCE.}

When assessing the effect of alleged unwanted conduct the following factors must be considered:

- The perception of the complainant;

- The other circumstances of the case; and

- Whether it is reasonable for the conduct to have that effect.

This is a subjective assessment balanced by other relevant factors such as the nature of the relationship between the parties (i.e. status/seniority) and the sensitivity of the complainant. If a complainant is overly sensitive it is unlikely the conduct complained of would constitute harassment.

\section{What is Unwanted Conduct?}

Unwanted conduct is not defined in the EqA but over the years case law has developed helpful clarification on how this is assessed, for example:

- It is well-established law that there is no need for a worker to have stated conduct is unwanted before it can constitute harassment:

- A one-off incident can constitute sexual harassment;

- The fact that a worker might have suffered in silence for some time (even years) does not mean that conduct cannot constitute harassment. This is likely to be relevant in
Some behaviour is easily categorised as sexual harassment, for example, the Employment Tribunal (ET) found no difficulty in determining that a male colleague commenting on a female colleague's breasts was sexual harassment. In a less clear cut case the ET determined that a female worker, who was aware her male colleagues were downloading pornographic images onto their computer screens but was not shown the images and didn't complain at the time, had not been subjected to sexual harassment. However, the Employment Appeal Tribunal (EAT) overturned this decision and determined that there had been sexual harassment as the conduct obviously undermined the claimant's dignity.

\section{Particular issues for dental practices} In the dental practice environment where staff such as dentists and dental nurses (in relation to whom there is a difference in status and often age) work in consistent, close and often isolated proximity to each other care needs to be taken to avoid the usual professional barriers in the workplace from being breached. Issues can arise for practices and individual employees whether intentional or not from conduct (including between colleagues of the same sex) that can cause offence, for example:

- A male dental associate seeking to build a rapport with a new young female dental nurse by asking inappropriately personal questions about the dental nurses' relationship with her partner and making comments about the dental nurses' appearance/physique;

- An informal environment in which professional boundaries are crossed daily due to banter involving jokes of a sexual nature and sexual innuendo without any action being taken to set appropriate standards;

- A failure to notify new staff (including locums) about unacceptable standards of behaviour including intentional physical contact being a summary dismissal matter; and

- Inadequate social media policies prohibiting staff from making offensive comments of a sexual nature about colleagues/patients.

\section{Action practices could face \\ Internal action}

Workers who believe that they have been sexually harassed may in the first instance raise internal complaints (grievances) about their treatment, which would usually involve an investigation followed by a formal meeting at which a decision would be made and the right of appeal against that decision offered. If the complaint was up-held it would most likely necessitate disciplinary action being taken against the harasser.

Such processes can be time-consuming and create difficult practical issues from the outset for small employers with limited resources. For example,

- If the complainant raises a serious harassment issue but states that $\mathrm{s} /$ he does not wish it to be addressed formally. Ordinarily if an issue is sufficiently serious it would be imprudent for the practice not to take steps to investigate notwithstanding the complainant's position;

- Consideration will have to be given to whether or not to suspend the worker accused of sexual harassment which could impact on the running of the practice;

- The issue will be sensitive and the confidentiality of those involved will require careful consideration. In small practices maintaining confidentiality is likely to be impossible thereby creating staff morale problems and potentially resulting in limited options being available to resolve the issue; and

- The need to notify relevant regulatory bodies and when this should be done. 
